\title{
Modeling and Regulator Design for Three-Input Power Systems with Decoupling Control
}

\author{
Yan $\mathrm{Li}^{\dagger}$, Trillion Q. Zheng ${ }^{*}$, Chuang Zhao ${ }^{*}$, and Jiayao Chen* \\ ${ }^{\dagger}$ School of Electrical Engineering, Beijing Jiaotong University, Beijing, China
}

\begin{abstract}
In hybrid renewable power systems, the use of a multiple-input dc/dc converter (MIC) leads to simpler circuit and lower cost, when compared to the conventional use of several single-input converters. This paper proposed a novel three-input buck/boost/buck-boost converter, which can be used in applications with various values of input voltage. The energy sources in this converter can deliver power to the load either simultaneously or individually in one switching period. The steady relationship, the power management strategy and the small-signal circuit model of this converter have been derived. With decoupling technology, modeling and regulator design can be obtained under multi-loop control modes. Finally, three generating methods of a multiple-input buck/boost/buck-boost converter is given, and this method can be extended to the other multiple-input $\mathrm{dc} / \mathrm{dc}$ converters.
\end{abstract}

Key words: Decoupling; Regulator design, Modeling, Multiple-input, Power management, Three-input

\section{INTRODUCTION}

The use of renewable energy sources and the development of power electronics systems for capitalizing such energy sources have received renewed interest in the past decade. Common forms of renewable energy sources include photovoltaic (PV) energy, hydro energy, and wind energy. Many of these sources are mutually complementary in the sense that they can be utilized simultaneously to maintain continuous delivery of power to the load. A number of renewable energy sources can be connected to a common $\mathrm{dc}$ bus through a number of independent single-input converters, and such configurations have been proposed for hybrid power systems[1], [2], as shown in Fig. 1(a). However, the use of a number of single-input converters leads to relatively complex configuration and high cost. Recently, the use of a multiple-input converter (MIC) to replace several single-input converters for reducing the complexity and cost of hybrid power systems has attracted increasing attention, as shown in Fig. 1(b). A MIC is capable

Manuscript received Mar. 22, 2012; revised Sep. 17, 2012

Recommended for publication by Associate Editor Jun-Keun Ji.

${ }^{\dagger}$ Corresponding Author: liyan@bjtu.edu.cn

Tel: +86-10-51684057-17, Fax: +86-10-51684029, Beijing Jiaotong University

${ }^{*}$ School of Electrical and Engineering, Beijing Jiaotong University, China of converting power from multiple power sources to a common load. The basic MIC was derived from a buck converter by adding more dc-input voltage sources in parallel with the original dc-input voltage source[3], [4]. As the available dc voltage sources have different magnitudes, and hence cannot be connected directly in parallel, the dc voltage sources are connected in parallel through a series-connected active switch. Only one power source is allowed to transfer energy to the load at a time which prevents more than two dc voltage sources from being connected in parallel. Such connection of dc-input voltage sources has been applied in buck-boost converters [5], [6], flyback, and forward converters [7], [8]. A multiple-input forward converter can be regarded as an isolated multiple-input buck-derived converter in which an isolation transformer is incorporated. All dc-input voltage sources together with their series-connected active switches have their own individual primary windings, but they share a secondary winding. Likewise, a multiple-input flyback converter can be regarded as an isolated multiple-input buck-boost converter. The control for such MICs is typically based on a time-multiplexing scheme. In order to overcome the limitation of the time-multiplexing scheme, some MICs have been proposed, which can successfully transfer power from different voltage sources to the load individually or simultaneously. The MICs proposed 
in [9]-[11] are an integration of a buck converter and a buck-boost converter, where the inductor and capacitor are shared by the two converters, thus leading to a reduced number of passive elements. The MICs proposed in [12]-[14] are essentially based on parallel connections at the output of a number of boost converters and buck-boost converters. Such MICs do not enjoy the advantage of reduced device and element counts. However, isolated multiple-input full-bridge boost converters [15]-[18] and half-bridge boost converters [19] share the output rectifier through a multiple-winding transformer. [20] proposes a systematic method to synthesize MICs, in which two types of MICs can be obtained. The first one allows one power source to transfer energy to the load at a time. The second one allows all of the energy sources to deliver power to the load either individually or simultaneously. A non-isolated three-input $\mathrm{dc} / \mathrm{dc}$ converter is generated by the method in [20] and it includes the second type. [1]-[20] have discussed the topologies, control strategies, and stability analyses of dual-input $\mathrm{dc} / \mathrm{dc}$ converters. However, this study will pay more attention to the optimizing design and the closed-loop stability analysis of three-input power systems.

In this paper, a novel three-input buck/boost/buck-boost converter will be discussed, which can be used in many hybrid renewable power systems. The three power sources in this converter can deliver energy to the load independently or simultaneously in one switching period. Detailed operation principles and the power management strategy of the three-input dc/dc converter will be illustrated in Sections II and III, respectively. Section IV and V show the small-signal circuit model and the closed-loop regulator design, respectively. Finally, a $400 \mathrm{~W}$ prototype was fabricated in the lab to verify the theoretical analysis and the experimental results will be shown in Section VI. In addition, corresponding multiple-input converters will be obtained based on the proposed generation method introduced in Section VII.

\section{OPERATION PRINCIPLE OF THE PROPOSED CONVERTER}

The buck/boost/buck-boost three-input converter shown in Fig. 2, is composed of two parallel connections, which are a boost cell and a hybrid cell. The hybrid cell is made up of a buck-boost cell with a built-in buck cell. $V_{i n 1}, V_{i n 2}$, and $V_{i n 3}$ are the three sources. $Q_{1}, Q_{2}$, and $Q_{3}$ are switches. $D_{1}, D_{2}$, and $D_{3}$ are freewheeling diodes. $L_{3}$ is a boost inductor. $L_{b}$ is a buffer inductor. $C_{f}$ is an output filter capacitor. $R_{L d}$ is the load. It should be noted that the three switches operate at the same switching frequency, and that the turn-on instants of the two switches are obliged to be synchronous.

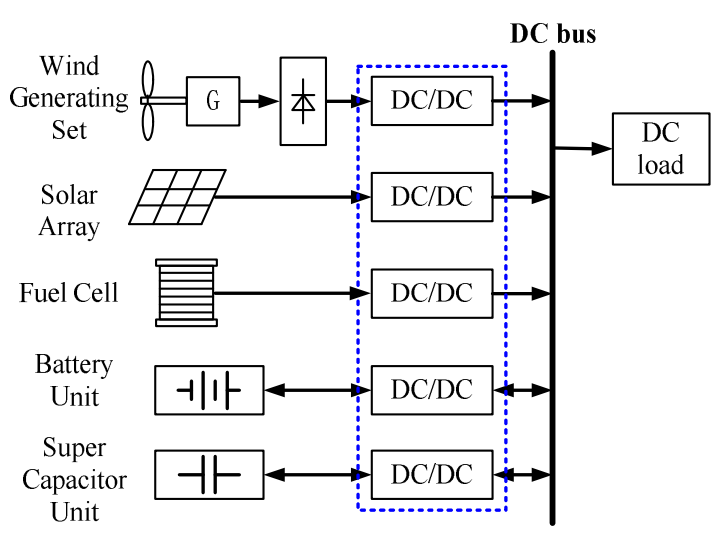

(a)

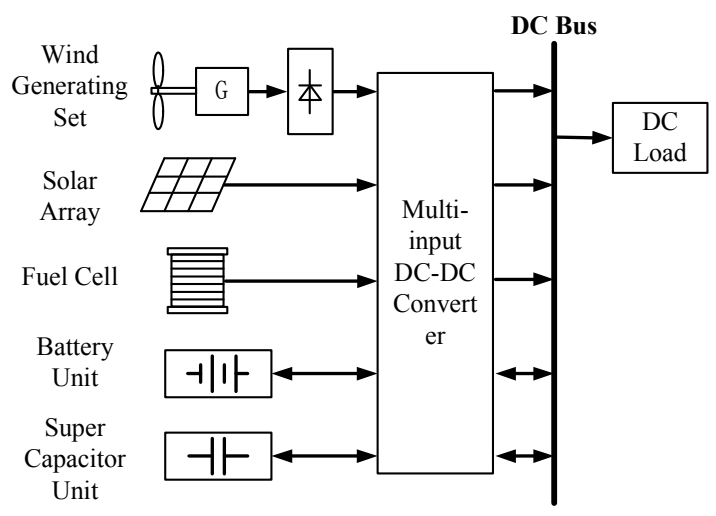

(b)

Fig. 1. General configuration of the hybrid renewable power system (a) with several single-input dc/dc converters (b) with a multiple-input dc/dc converter

Fig.3 shows the key waveforms for the continuous-conduction mode of operation. There are four different operation stages according to the states of the three switches in one switching period.

Stage I $\left[\mathrm{t}_{0}-\mathrm{t}_{1}\right]$ : Switches $Q_{1}, Q_{2}$ and $Q_{3}$ are on. This will result in a positive voltage $V_{L 3}=V_{i n 3}, V_{L b}=V_{i n 1}+V_{i n 2}$ across the two inductors. The inductor currents, $i_{L b}$ and $i_{L 3}$, increase linearly.

Stage II $\left[\mathrm{t}_{1}-\mathrm{t}_{2}\right]$ : Switch $Q_{1}$ turns off, while switches $Q_{2}$ and $Q_{3}$ are still in conduction mode, $V_{L 3}=V_{i n 3}$. This voltage results in $i_{L 3}$ increasing linearly. $V_{L b}=V_{i n 2}-V_{o}$, so that when $V_{o}<$ $V_{i n 2}, i_{L b}$ increases linearly, and when $V_{o}>V_{i n 2}, i_{L b}$ decays linearly.

Stage III [ $\left.\mathrm{t}_{2}-\mathrm{t}_{3}\right]$ : Switches $Q_{1}$ and $Q_{2}$ are off, while switch $Q_{3}$ is conductive. $V_{L 3}=V_{i n 3}$ which results in $i_{L 3}$ increasing linearly. $V_{L b}=-V_{o}$, which results in $i_{L b}$ decaying linearly, while $L_{b}$ freewheels through diodes $D_{1}$ and $D_{2}$.

Stage IV [ $\left.\mathrm{t}_{3}-\mathrm{t}_{4}\right]$ : Switches $Q_{1}, Q_{2}$, and $Q_{3}$ are all off. $V_{L 3}=V$ ${ }_{i n 3}-V_{o}$, which results in $i_{L 3}$ decreasing linearly. $V_{L b}=-V_{o}$, which results in $i_{L b}$ decaying linearly.

An equivalent circuit is shown in Fig. 2 when sources 1, 2 


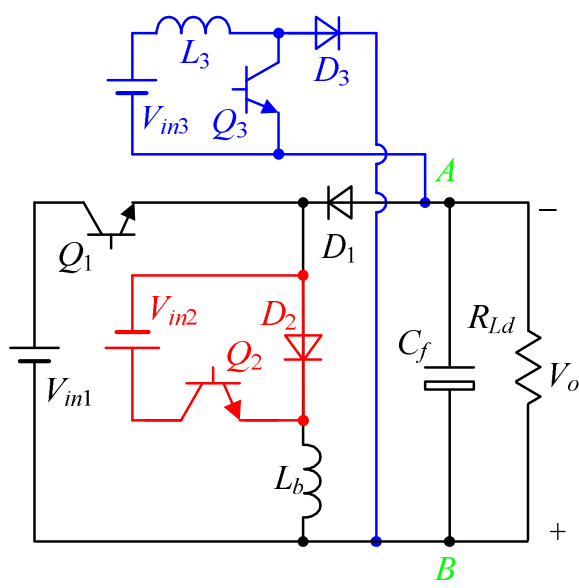

Fig. 2. Three-input buck/boost/buck-boost converter.

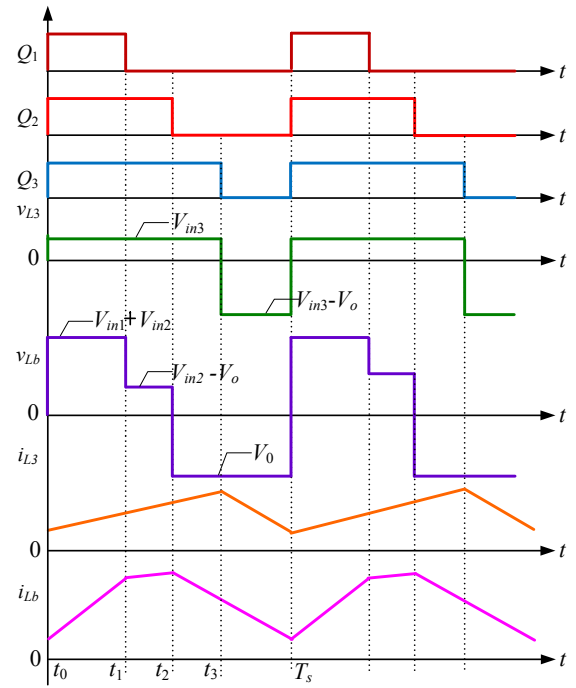

Fig. 3. Key waveforms of three-input buck/boost/buck-boost converter.

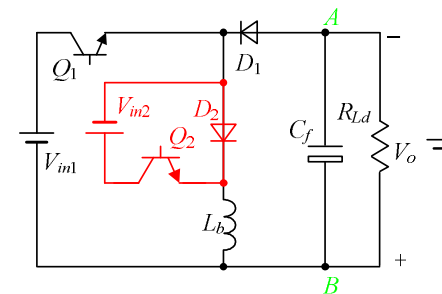

(a)

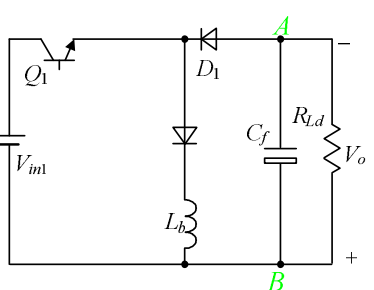

(b)
Fig. 4. Equivalent circuit of (a) operation mode II (b) operation mode III.

and 3 work together. An equivalent circuit is shown in Fig. 4(a) when sources 1 and 2 work together. The equivalent circuit in Fig. 4(b) shows when source 1 works independently.

Using the volt-second balance of inductor $L_{b}$ and inductor $L_{3}$, the expression of the output voltage in the steady-state analysis can be obtained, as shown in Eq. (1).

$$
\begin{aligned}
& V_{o}=V_{i n 1} \cdot \frac{D_{y 1}}{1-D_{y 1}}+V_{i n 2} \cdot \frac{D_{y 2}}{1-D_{y 1}} \\
& V_{o}=V_{i n 3} \cdot \frac{1}{1-D_{y 3}}
\end{aligned}
$$

The average value of the output current is $I_{o}=I_{o 3}+I_{o 12}$, where $I_{o}$ is the total output current, $I_{o 3}$ is the output current of source 3 , and $I_{o 12}$ is the sum of the output current of sources 1 and 2.

Neglecting the power losses associated with all of the circuit elements, the input power equals the output power.

$$
\begin{gathered}
P_{o}=P_{12}+P_{3} \\
P_{12}=V_{i n 1} \cdot I_{i n 1}+V_{i n 2} \cdot I_{i n 2}=V_{o} \cdot I_{o 12} \\
P_{3}=\frac{V_{i n 3}}{1-D_{y 3}} \cdot I_{o 3}
\end{gathered}
$$

where $P_{o}$ is the total output power required by the load, $P_{3}$ is the output power from source 3 , and $P_{12}$ is the sum of the output power of sources 1 and 2 .

Therefore:

$$
\begin{aligned}
& I_{i n 1}=\frac{D_{y 1}}{1-D_{y 1}} I_{o 12} \\
& I_{i n 2}=\frac{D_{y 2}}{1-D_{y 1}} I_{o 12} \\
& I_{i n 3}=\frac{1}{1-D_{y 3}} I_{o 3}
\end{aligned}
$$

where $I_{i n 1}, I_{i n 2}$, and $I_{i n 3}$ are the average currents from sources 1 , 2 , and 3 .

$$
\begin{aligned}
& I_{L b}=I_{o 12} /\left(1-D_{y 2}\right) \\
& I_{L 3}=I 03 /\left(1-D_{y 3}\right)
\end{aligned}
$$

\section{POWER MANAGEMENT STRATEGY}

It is well known that the power management strategy in a three-input $\mathrm{dc} / \mathrm{dc}$ converter includes output voltage regulation and input power distribution over the three power sources.

In a solar-wind complementary power system, a three-input buck/boost/buck-boost $\mathrm{dc} / \mathrm{dc}$ converter is employed and the energy of solar array should have the priority in use. Consequently, the solar array is the major power source (source 1), the wind turbine is a minor source (source 2) and the battery is a back-up source (source 3 ). This paper introduces a master-slave control mode to distribute the input power over the three sources [10]. The input power distribution strategy is that the demanded power of the load is 


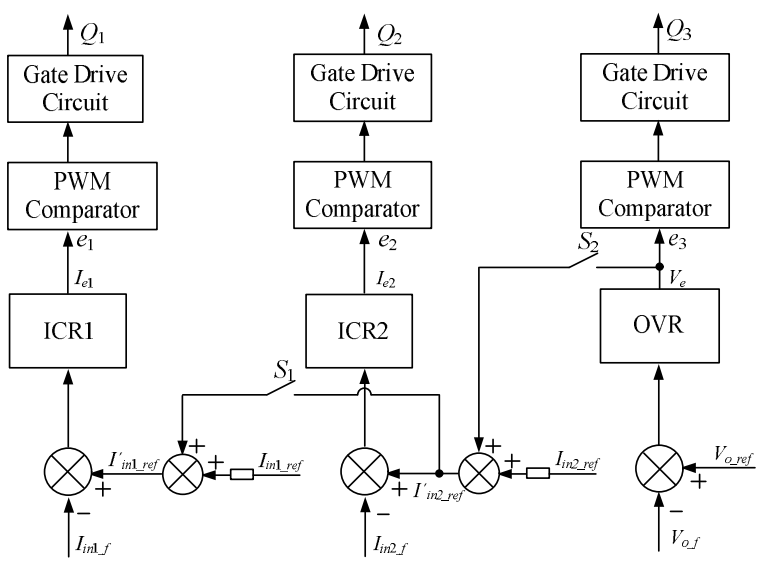

Fig. 5. Block diagram of control system.

provided by sources 1 and 2 as much as possible and the rest is provided by source 3 . When the load power is more than total power of sources 1 and 2, and the remnant power will be provided by source 3 . When the load power is more than the power of source 1 and less than the total power of sources 1 and 2, the remnant power will be provided by source 2 . Meanwhile, source 3 is not used.

When the input voltage is provided, the control of the input power can be implemented by controlling its input current. Therefore, the control system is composed of two input current loops and one output voltage loop. Fig. 5 shows a block diagram of the control system, where $v_{\text {oref }}$ is the output voltage reference, $I_{\text {in } 1 \text { ref }}$ is the input current reference of source $1, I_{\text {in2 } 2 \text { ref }}$ is the input current reference of source 2 and the corresponding power are $P_{i n 1_{1} \text { ref }}$ and $P_{i n 2_{2} \text { ref }}$, respectively. ICR1 is the input current regulator of power source 1, ICR2 is the input current regulator of power source 2, and OVR is the output voltage regulator. There are three operation modes in this hybrid power system, which are illustrated as follows.

Operation mode I: In this mode $P_{o}>P_{i n 1 \_\max }+P_{i n 2 \_ \text {max }}$, where $P_{o}$ is the output power, $P_{i n 1 \_\max }$ is the maximal power of source 1 , and $P_{\text {in2_max }}$ is the maximal power of source 2 . These three power sources provide energy to the load simultaneously. In this case, the output of voltage regulator $V_{e}$ is positive, while switches $S_{1}$ and $S_{2}$ off. Then ICR1, ICR2 and OVR work independently. $I_{i n 1_{\text {ref }}}$ is the input current reference value depending on the maximal power of source 1 , which makes it provide the maximal power. $I_{\text {in2_ref }}$ is the input current reference value depending on the maximal power of source 2, which makes it provide the maximal power. The voltage regulator can be used to keep the output voltage constant when source 3 covers the rest of the load power.

Operation mode II: With the decrease in the load power, $P_{\text {in1_max }}<P_{o}<P_{\text {in1_max }}+P_{\text {in2_max }}$. Source 1 provides most of the power, where the rest load power is provided by source 2 . In this case, $V_{e}$ is negative, which turns $Q_{3}$ off and enables $S_{2}$ to turn on. Then, the sum of the output of $V_{e}$ and $I_{\text {in2_ref, }}$, makes the input current of source 2 decrease. $S_{1}$ stays off. At this time, ICR2 and OVR constitute a double closed-loop, where the current loop is the inner loop and the voltage loop is the outer one. The voltage loop can accommodate $D_{y 2}$ to make source 2 cover the rest of the load power, thus keeping the output voltage constant.

Operation mode III: With the further decrease of the load power, $P_{o}<P_{\text {in1_max }}$. In this circumstance, $V_{e}$ is negative, which turns $Q_{3}$ off and enables $S_{2}$ to turn on. The sum of $V_{e}$ and $I_{i n 2 \_ \text {ref }}$, is negative, which makes $Q_{2}$ turn off. In other words, it shuts down source 2. $S_{1}$ is on, diminishing $I_{\text {in } 1 \text { ref }}$, which diminishes the input current. At this time, OVR and ICR1 constitute a double closed-loop, where the current loop is the inner loop and the voltage loop is the outer one. The voltage loop can accommodate $D_{y 1}$ to alter the output power according to the load, thus keeping the output voltage stable.

\section{SMALl-Signal CiRCUIT MODEL}

To design the three-input closed-loop control system, a small-signal model of the three-input buck/boost/buck-boost converter in the three different operation modes is needed. State space averaging is a powerful method for calculating the steady-state values of voltages and currents and for extracting the small-signal model of switching converters. Therefore, a small-signal circuit model of the three-input $\mathrm{dc} / \mathrm{dc}$ converter can be easily constructed using the state space averaging method [16], as shown in Figs. 6, 7 and 8. Thus the following small-signal equations can be obtained. It should be noted that the small-signal modeling is based on the continuous-conduction mode.

The plant transfer function matrix for the three-input $\mathrm{dc} / \mathrm{dc}$ converter is given by:

$$
Y(s)=\left(\begin{array}{l}
\hat{i}_{i n 1}(s) \\
\hat{i}_{i n 2}(s) \\
\hat{v}_{o}(s)
\end{array}\right)=\left(\begin{array}{ccc}
G_{11}(s) & G_{12}(s) & 0 \\
G_{21}(s) & G_{22}(s) & 0 \\
0 & 0 & G_{3}(s)
\end{array}\right)\left(\begin{array}{c}
\hat{d}_{y 1}(s) \\
\hat{d}_{y 2}(s) \\
\hat{d}_{y 3}(s)
\end{array}\right)
$$

The multiple transfer functions of the power plant are derived as follows:

$$
\begin{gathered}
G_{11}(s)=\left.\frac{\hat{i}_{i n 1}(s)}{\hat{d}_{y 1}(s)}\right|_{\hat{d}_{y 2}(s)=0}=\frac{D_{y 1} \cdot\left[C_{f} s\left(R_{L d}+R_{C}\right)+1\right] \cdot\left(V_{i n 1}+V_{o}\right)+D_{y 1} V_{o}}{L_{b} C_{f} s^{2}\left(R_{L d}+R_{C}\right)+s L_{b}+\left(1-D_{y 1}\right)^{2} R_{L d}}+I_{L b}(8) \\
G_{12}(s)=\left.\frac{\hat{i}_{i n 1}(s)}{\hat{d}_{y 2}(s)}\right|_{\hat{d}_{y 1}(s)=0}=\frac{D_{y 1} \cdot\left[C_{f} s\left(R_{L d}+R_{C}\right)+1\right] \cdot V_{i n 2}}{L_{b} C_{f} s^{2}\left(R_{L d}+R_{C}\right)+s L_{b}+\left(1-D_{y 1}\right)^{2} R_{L d}} \\
G_{21}(s)=\left.\frac{\hat{i}_{i n 2}(s)}{\hat{d}_{y 1}(s)}\right|_{\hat{d}_{y 2}(s)=0}=\frac{D_{y 2}\left[C_{f} s\left(R_{L d}+R_{C}\right)+1\right] \cdot\left(V_{i n 1}+V_{o}\right)+D_{y 2} V_{o}}{L_{b} C_{f} s^{2}\left(R_{L d}+R_{C}\right)+s L_{b}+\left(1-D_{y 1}\right)^{2} R_{L d}}(10) \\
G_{22}(s)=\left.\frac{\hat{i}_{i n 2}(s)}{\hat{d}_{y 2}(s)}\right|_{\hat{d}_{y 1}(s)=0}=\frac{D_{y 2}\left[C_{f} s\left(R_{L d}+R_{C}\right)+1\right] \cdot V_{i n 2}}{L_{b} C_{f} s^{2}\left(R_{L d}+R_{C}\right)+s L_{b}+\left(1-D_{y 1}\right)^{2} R_{L d}}+I_{L b}(11)
\end{gathered}
$$




$$
G_{3}(s)=\frac{\hat{v}_{o}(s)}{\hat{d}_{y 3}(s)}=\frac{V_{o} \cdot\left(1-D_{y 3}\right) \cdot R_{L d}-\frac{V_{o}}{\left(1-D_{y 3}\right)} L_{3} s}{L_{3} C_{f} s^{2}\left(R_{L d}+R_{C}\right)+s L_{3}+\left(1-D_{y 1}\right)^{2} R_{L d}}
$$

where $G_{11}(s), G_{12}(s), G_{21}(s)$ and $G_{22}(s)$ are the transfer functions between $\hat{i}_{i n}(s)$ and $\hat{d}_{y}(s), G_{3}(s)$ is the transfer function between $\hat{v}_{o}(s)$ and $\hat{d}_{y}(s)$, which can be obtained from (8) to (12). In operation mode I, $d_{y 1}, d_{y 2}$ and $d_{y 3}$ are the three control variables, and $i_{i n 1}, i_{i n 2}$ and $v_{o}$ are the three controlled variables. In operation mode II, $D_{y 3}=0$ and source 3 does not power the load.

By substituting $\hat{v}_{i n 3}(s)=0, \hat{i}_{i n 3}(s)=0, \hat{d}_{y 3}(s)=0$ and $D_{y 3}=0$ into (8) - (12), the output equations of operation mode II can be obtained. In operation mode III, $D_{y 2}=0, D_{y 3}=0$ and sources 2 and 3 do not power the load. When all three sources power the load, the system works in operation mode I, and the small-signal circuit model consists of two segments: (1) the buck/buck-boost hybrid cell and (2) the boost cell, as shown in Fig. 6 and 7, respectively. When source 3 is not working, which is in operation mode II, the three-input buck/boost/buck-boost converter can be regarded as a double-input buck/buck-boost converter, source 2 will be controlled in the double closed-loop, and the small signal circuit model is shown in Fig. 6. When sources 2 and 3 are not working, the three-input buck/boost/buck-boost converter can be regarded as a single-input buck-boost converter, and the small signal circuit model is shown in Fig. 8.

\section{Closed-Loop Regulator Design with DECOUPLING CONTROL}

According to Fig.5, a system block diagram in the three operation modes can be developed. They are shown in Fig. 9, where $G_{c r 1}(s), G_{c r 2}(s)$ and $G_{v \mathrm{r}}(s)$ are the transfer functions of ICR1, ICR2 and OVR, respectively. The transfer function of the PWM modulator $G_{P W M}(\mathrm{~s})=1 / V_{m}$, where $V_{m}$ is the peak voltage of the saw-tooth. Since the input current is pulsating, an RC filter is needed. The transfer functions of the filters $G_{c f 1}$ (s) $=1 /\left(\mathrm{s} \cdot R_{1} C_{1}+1\right)$ and $G_{c f 2}(\mathrm{~s})=1 /\left(\mathrm{s} \cdot R_{2} C_{2}+1\right)$, where $R_{1}, R_{2}$, $C_{1}$ and $C_{2}$ are the resistors and capacitors of the RC filter. The voltage sensor gain $G_{v f}(\mathrm{~s})=K$.

$\hat{d}_{y 1}(s)$ and $\hat{d}_{y 2}(s)$ affect the input current of both source 1 and source 2 due to the existence of $G_{12}(s)$ and $G_{21}(s)$ when the three sources power the load simultaneously (Refer to Fig. 9(a)). In other words, the two input current loops are coupled, which makes it difficult to design ICR1 and ICR2. However, the output voltage closed-loop has nothing to do with the two input current loops, which are controlled by $\hat{d}_{y 3}(s)$ (Refer to Fig. 9(b)).

$D_{y 3}$ will go to zero when source 1 and 2 power the load simultaneously (Refer to Fig. 9(c)). Similar to operation mode

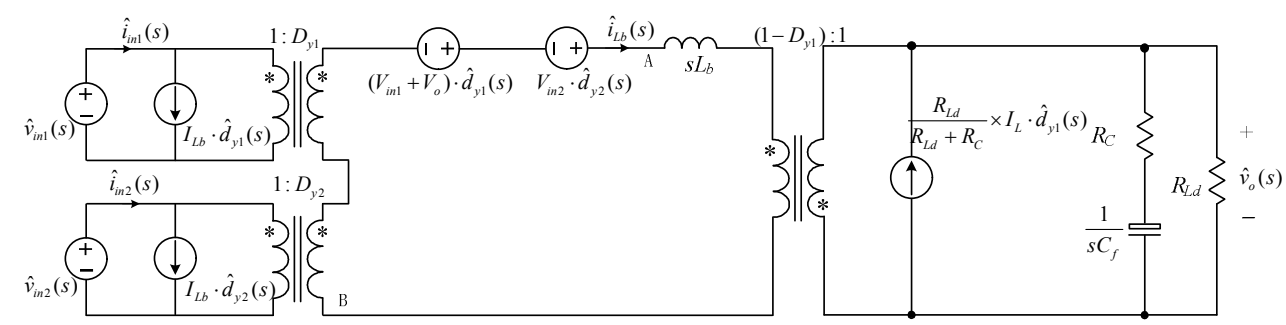

Fig. 6. Small-signal circuit model of Buck/buck-boost converter in operational mode I and II.

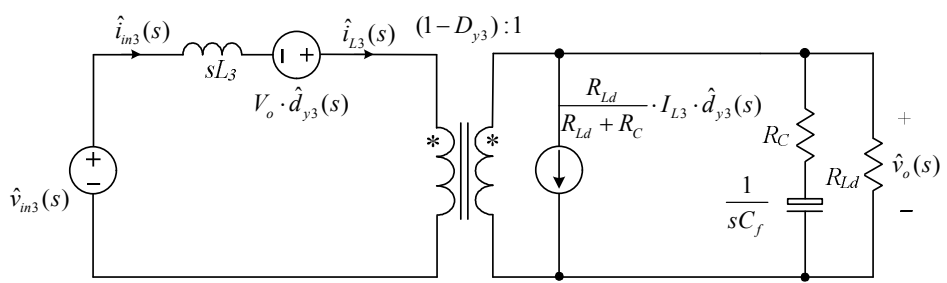

Fig. 7. Small-signal circuit model of Boost converter in operation mode I.

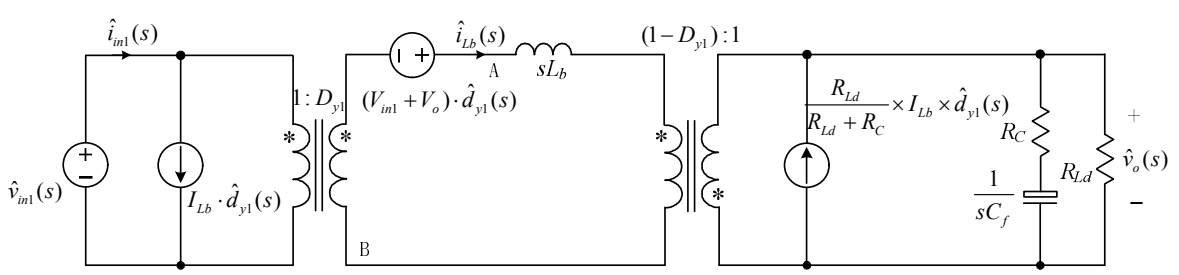

Fig. 8. Small-signal circuit model of the three-input buck/boost/buck-boost DC/DC converter in operation mode III. 
I, $\hat{d}_{y 1}(s)$ and $\hat{d}_{y 2}(s)$ affect the input current of both source 1 and the output voltage due to the existence of $G_{12}(s)$ and $G_{21}(s)$. In other words, the input current loop and the output voltage loop are coupled, which makes it difficult to design ICR 1 and OVR in operation mode II. Source 2 will work in a typical double closed-loop system. The output voltage loop is the outer loop, and the current loop of source 2 is the inner one. In Fig. 9(c), $F_{2}(\mathrm{~s})$ is the transfer function between $\hat{v}_{\mathrm{o}}(s)$ and $\hat{i}_{i n 2}(s)$, which is expressed in Eq. (13).

$$
F_{2}(s)=\frac{\hat{v}_{o}(s)}{\hat{i}_{i n 2}(s)}=\frac{1-D_{y 1} \cdot R_{l d}}{D_{y 2}\left[C_{f} s\left(R_{l d}+R_{C}\right)+1\right]}
$$

$D_{y 2}$ and $D_{y 3}$ both go to zero when source 1 powers the load independently (Refer to Fig. 9(d)). The output voltage closed-loop is a typical single-input single-output system, which is used to regulate the output voltage. In Fig. 9(d), $F_{1}(s)$ is the transfer function between $\hat{v}_{\mathrm{o}}(s)$ and $\hat{i}_{i n 1}(s)$, which is expressed in Eq. (14).

$$
F_{1}(s)=\frac{\hat{v}_{o}(s)}{\hat{i}_{i n 1}(s)}=\frac{1-D_{y 1} \cdot R_{l d}}{D_{y 1}\left[C_{f} s\left(R_{l d}+R_{C}\right)+1\right]}
$$

As a result, ICR1, ICR2 and OVR work in multiple operation modes, and they should be carefully designed to ensure stability and a better dynamic response for all of the operation modes. It is a coupling system in operation modes I and II. They should be decoupled before the regulators are designed.

In a general feedback system, the requirements for stability and dynamic response imposes constraints on the loop gain since all of the information on the closed-loop transfer function can be obtained from it. Thus the loop gains of the three loops in the three operation modes should be derived first.

\section{A. Operation Mode I}

The coupling problem of the two current closed-loops shown in Fig. 9(a), can be decoupled by inserting the decoupling matrix, $G^{*}(s)$, which is given as Eq. (16). The decoupled transfer function matrix of the converter is defined as $G^{\wedge}(s)$, which is a standard diagonal matrix. If the two current loops can be decoupled, the two input current regulators can be design independently. The decoupled transfer function matrix block diagram of the control system is shown in Fig. 10. The expression of $G^{\wedge}(s)$ is shown in Eq.

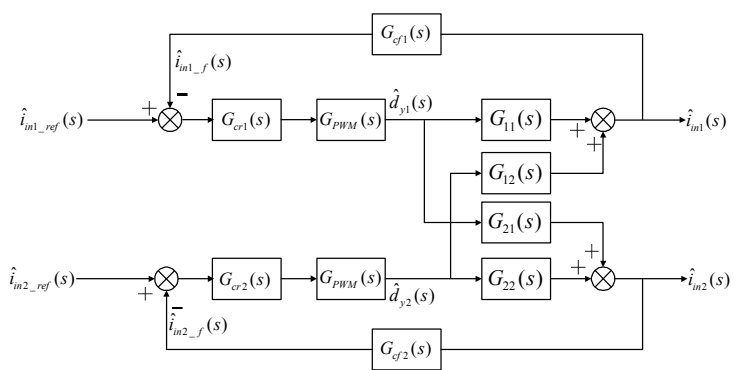

(a)

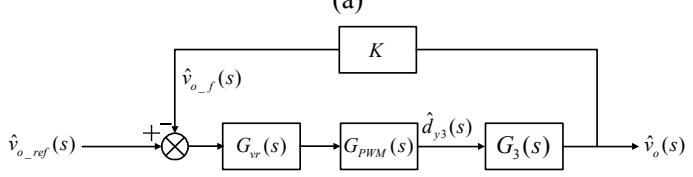

(b)

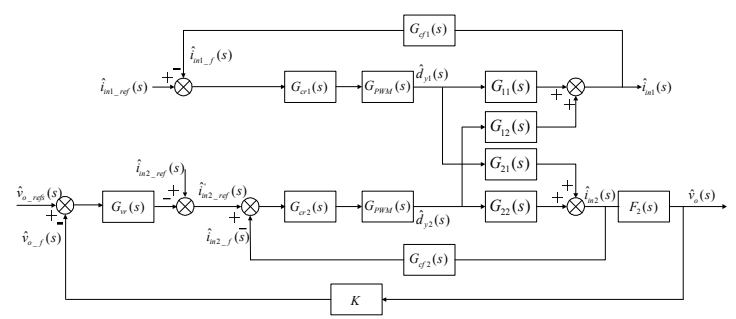

(c)

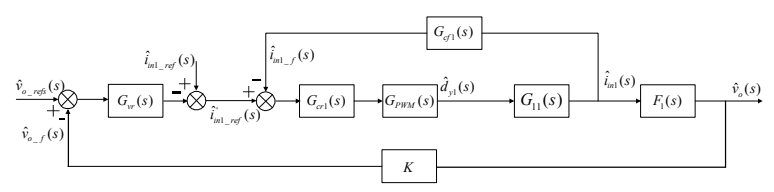

(d)

Fig. 9. Small-signal model (a) of hybrid cell in operation mode I (b) of boost cell in operation mode I (c) in operation mode II (d) in operation mode III.

(17).

$$
\begin{gathered}
\left(\begin{array}{ll}
G_{11}(s) & G_{12}(s) \\
G_{21}(s) & G_{22}(s)
\end{array}\right)\left(\begin{array}{ll}
G_{11}^{*}(s) & G_{12}^{*}(s) \\
G_{21}^{*}(s) & G_{22}^{*}(s)
\end{array}\right)=\left(\begin{array}{cc}
G_{11}^{\wedge}(s) & 0 \\
0 & G_{22}^{\wedge}(s)
\end{array}\right)(15) \\
\left(\begin{array}{cc}
G_{11}^{*}(s) & G_{12}^{*}(s) \\
G_{21}^{*}(s) & G_{22}^{*}(s)
\end{array}\right)=\left(\begin{array}{cc}
1 & -\frac{G_{12}(s)}{G_{11}(s)} \\
-\frac{G_{21}(s)}{G_{22}(s)} & 1
\end{array}\right) \\
\left(\begin{array}{cc}
G_{11}^{\wedge}(s) & 0 \\
0 & G_{22}^{\wedge}(s)
\end{array}\right)=\left(\begin{array}{cc}
G_{11}(s)-G_{12}(s) \frac{G_{21}(s)}{G_{22}(s)} & 0 \\
0 & G_{22}(s)-G_{21}(s) \frac{G_{12}(s)}{G_{11}(s)}
\end{array}\right)
\end{gathered}
$$

The decoupling process is shown in Fig. 10, and the decoupled loop gain of the two input current loops are $T_{i_{-}}(\mathrm{s})$ and $T_{i_{2}}(\mathrm{~s})$, which are expressed as:

$$
\begin{aligned}
& T_{i_{-} 1}(s)=G_{c r 1}(s) G_{P W M}(s) G_{c f 1}(s) G_{11}^{\wedge}(s) \\
& T_{i_{-} 2}(s)=G_{c r 2}(s) G_{P W M}(s) G_{c f 2}(s) G_{22}^{\wedge}(s)
\end{aligned}
$$




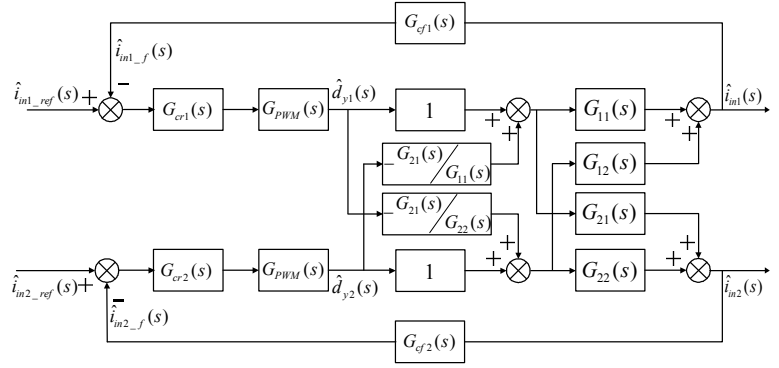

(a)

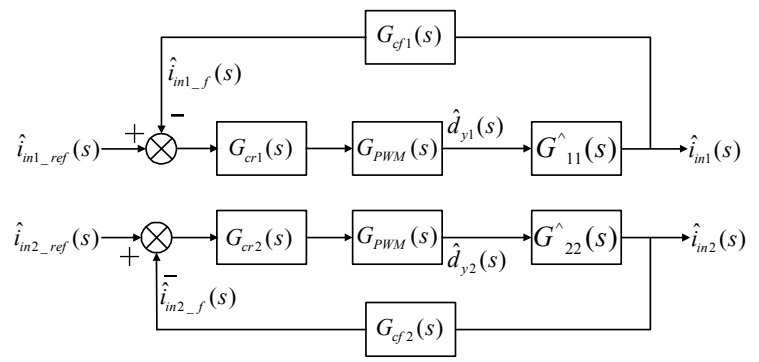

(b)

Fig. 10 Block diagram of the control system in operation mode I. (a) Inserting decoupling matrix. (b) Decoupled.

The loop gain of the single output voltage closed-loop in operation mode I, which can be obtained from Fig. 9(b), is:

$$
T_{v}(s)=G_{v r}(s) G_{P W M}(s) G_{3}(s) K
$$

The original open-loop Bode plots for the three loops of the three-input converter with $G_{c r}(\mathrm{~s})=1$ and $G_{v r}(\mathrm{~s})=1$ are illustrated with a dashed line and the compensated open-loop Bode plots for them are illustrated with a solid line in Fig. 11.

It can be observed that the loop bandwidth of the input current closed-loop of source 1 is $3 \mathrm{kHz}$, and the phase angle margin is $65^{\circ}$, as shown in Fig. 11(a). The loop bandwidth of the input current closed-loop of source 1 is $8 \mathrm{kHz}$, and the phase angle margin is $85^{\circ}$, as shown in Fig. 11(c). The loop bandwidth of the output voltage closed-loop of source 1 is $700 \mathrm{~Hz}$, and the phase angle margin is $40^{\circ}$, as shown in Fig. 11(e). The Bode plot simulation is made to verify the design of the closed-loop by PSIM (AC frequency) sweep. Figs. 11(b), 11(d), and 11(c) show the simulation results of the three loops. These simulation results are fundamentally consistent with the theoretical analysis.

\section{B. Operation Mode II}

Similarly, the input current loop of source 1 and the voltage loop can be decoupled in this case. A block diagram of the control system with decoupling control of the input current loop and the output voltage loop is shown in Fig. 12. Ti_1(s), Ti_2i(s) and Ti_2v(s) are the loop gain of the input current loop of source 1, the input current inner loop of source 2 and the output voltage outer loop. According to the decoupled block diagram shown in Fig. 12(b), Ti_1(s), Ti_2i(s) and Ti_2v(s) are given by Eqs. (21), (22) and (23).

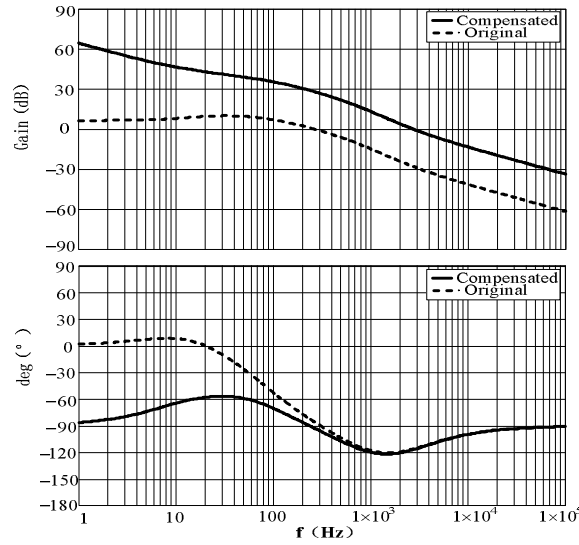

(a)
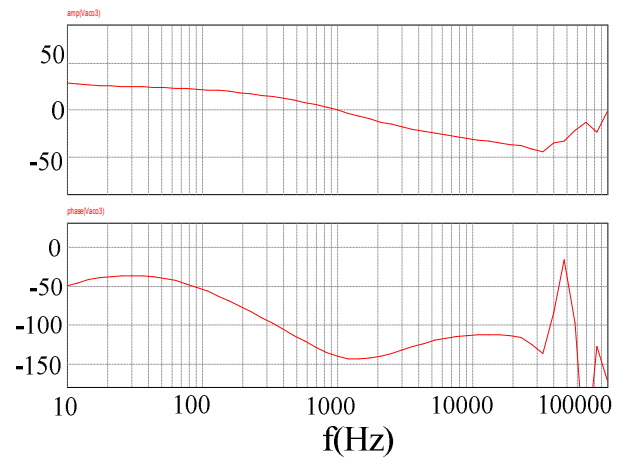

(b)

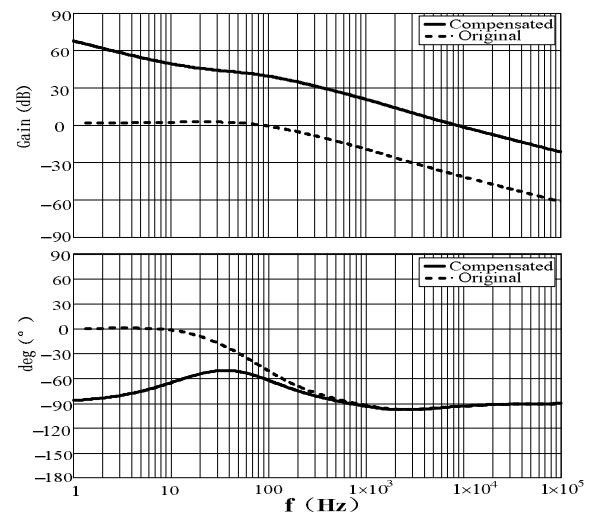

(c)

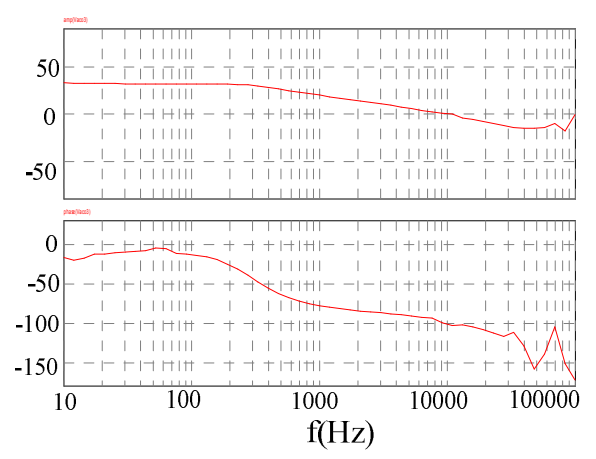

(d) 


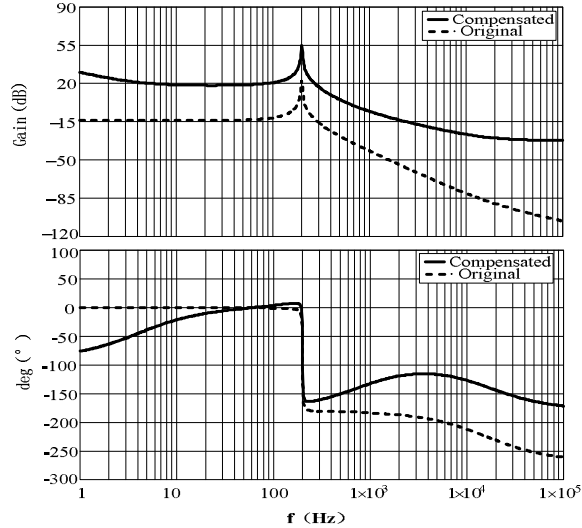

(e)

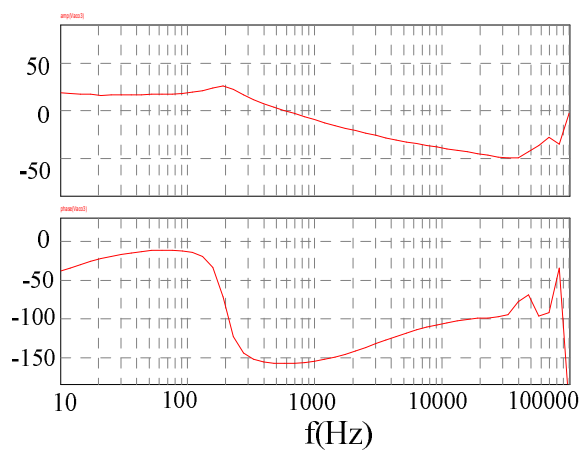

(f)

Fig. 11. Bode plots in operation mode I of (a) input current loop of source 1 by Mathcad (b) input current loop of source 1 by PSIM (c) input current loop of source 2 by Mathcad (d) input current loop of source 2 by PSIM (e) output voltage loop by Mathcad (f) output voltage loop by PSIM.

$$
\begin{gathered}
T_{i_{-} 1}(s)=G_{c r 1}(s) G_{P W M}(s) G_{c f 1}(s) G_{11}^{\wedge}(s) \\
T_{i_{-} 2 i}(s)=G_{c r 2}(s) G_{P W M}(s) G_{c f 2}(s) G_{22}^{\wedge}(s) \\
T_{i_{-} 2 v}(s)=G_{v r}(s) F_{2}(s) K \frac{G_{P W M}(s) G_{c r 2}(s) G_{22}(s)}{1+G_{P W M}(s) G_{c f 2}(s) G_{22}^{\wedge}(s) G_{c r 2}(s)}
\end{gathered}
$$

It can be observed that the loop bandwidth of the input current loop of source 1 is $3 \mathrm{kHz}$, and the phase angle margin is $50^{\circ}$, as shown in Fig. 13(a). The loop bandwidth of the input current inner loop of source 2 is $8 \mathrm{kHz}$, and the phase angle margin is $90^{\circ}$, as shown in Fig. 13(c). The loop bandwidth of the output voltage outer loop is $900 \mathrm{~Hz}$, which is approximately one-tenth that of the input current inner loop. The phase angle margin is $100^{\circ}$, as shown in Fig. 13(e). The Bode plot simulation is made to verify the design of the closed-loop by PSIM (AC frequency) sweep. Figs. 13(b), 13(d), and 13(f) show the simulation results of the three loops. These simulation results are fundamentally consistent with the theoretical analysis.

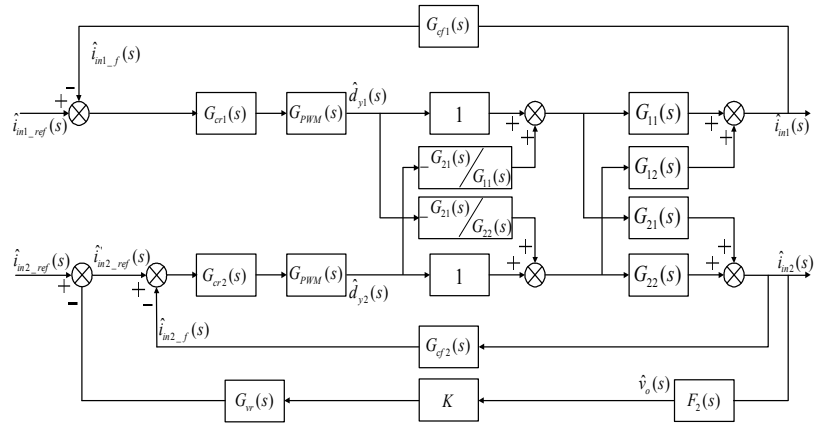

(a)

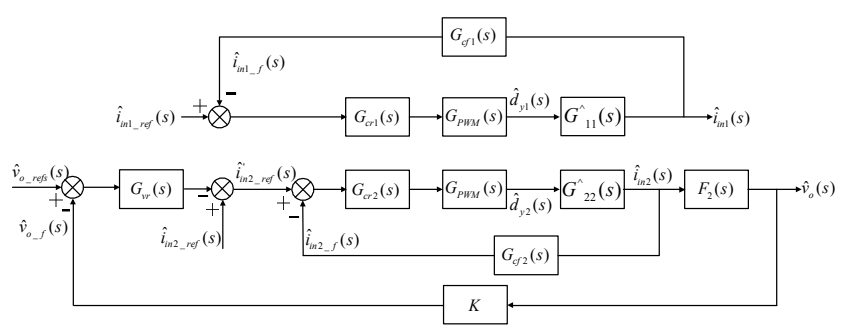

(b)

Fig. 12 Block diagram of the control system in operation mode II. (a) Inserting decoupling matrix. (b) Decoupled.

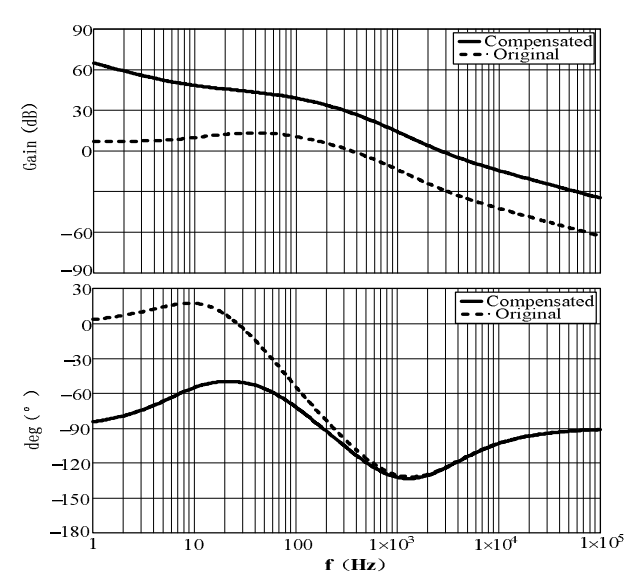

(a)

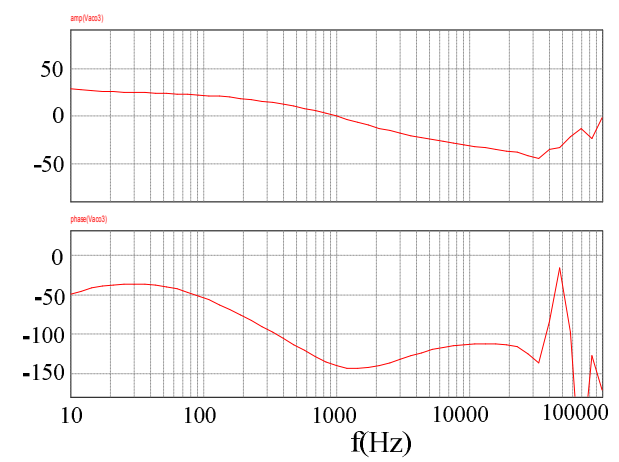

(b) 


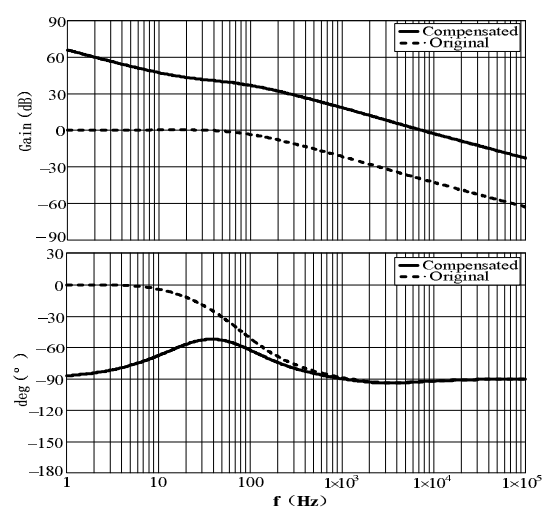

(c)

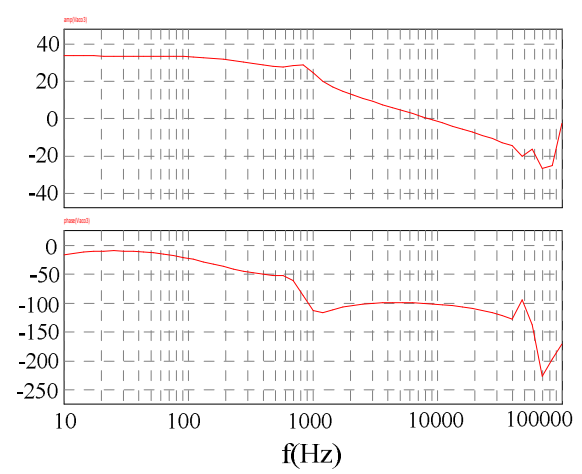

(d)

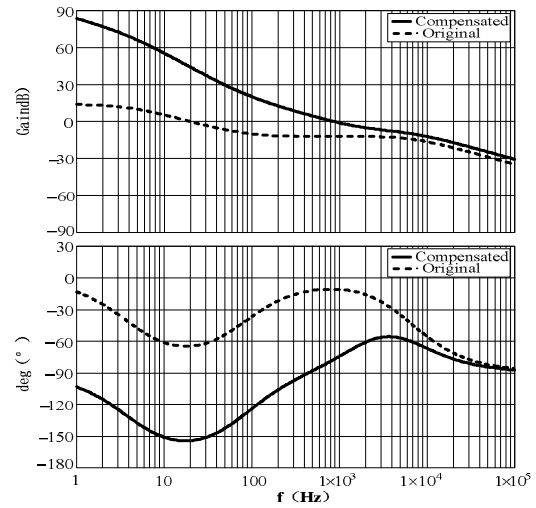

(e)

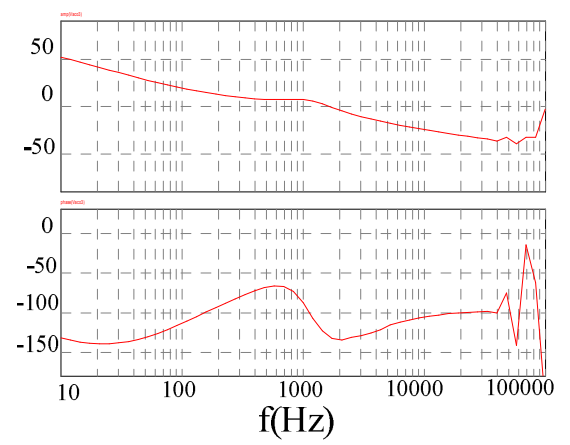

(f)

Fig. 13. Bode plots in operation mode II of (a) input current loop of source 1 by Mathcad (b) input current loop of source 1 by PSIM (c) input current inner loop of source 2 by Mathcad (d) input current inner loop of source 2 by PSIM (e) output voltage outer loop by Mathcad (f) output voltage outer loop by PSIM.

\section{Operation Mode III}

According to the small-signal model of operation mode III, which is shown in Fig. 9(d), $T_{i 1 \mathrm{i}}(\mathrm{s})$ and $T_{i \text { 1vi }}(\mathrm{s})$ are given by Eqs. (24) and (25). It can be observed that the loop bandwidth of the compensated input current inner closed-loop of source 1 is $2.5 \mathrm{kHz}$, and the phase angle margin is $30^{\circ}$, as shown in Fig. 14(a). The loop bandwidth of the compensated output voltage outer closed-loop is $300 \mathrm{~Hz}$, and the phase angle margin is $85^{\circ}$, as shown in Fig. 14(c). The Bode plot simulation is made to verify the design of the closed-loop by PSIM (AC frequency) sweep. Figs. 14(b) and 14(d) show the simulation results of the two loops. These simulation results are fundamentally consistent with the theoretical analysis.

$$
\begin{gathered}
T_{i_{-} 1 i}(s)=G_{c r 1}(s) G_{P W M}(s) G_{c f 1}(s) G_{1}(s) \\
T_{i_{-} 1 v}(s)=G_{v r}(s) F_{1}(s) K \frac{G_{c r 1}(s) G_{P W M}(s) G_{1}(s)}{1+G_{c r 1}(s) G_{P W M}(s) G_{c f 1}(s) G_{1}(s)}
\end{gathered}
$$

\section{EXPERIMENTAL RESULTS}

The presented control strategy, the small-signal modeling and the regulator design have been verified on a $400 \mathrm{~W}$ prototype of a buck/boost/buck-boost three-input $\mathrm{dc} / \mathrm{dc}$ converter.

The main performance index will be shown as follows:

- Input voltage of source 1: $V_{i n 1}=150 \mathrm{~V}$;

- Input voltage of source 2: $V_{\text {in } 2}=125 \mathrm{~V}$;

- Input voltage of source 3: $V_{i n 3}=50 \mathrm{~V}$;

- Input current reference of source 1: $I_{\text {in1_ref }}=0.9 \mathrm{~A}$, i.e., and $P_{\text {in1_ref }}=135 \mathrm{~W}$;

- Input current reference of source 2: $I_{\text {in } 1 \text { ref }}=1 \mathrm{~A}$, i.e., and $P_{\text {in1_ref }}=125 \mathrm{~W}$;

- Output voltage: $V_{o}=100 \mathrm{~V}$;

- $\quad$ Rated power: $P_{o} \quad 400 \mathrm{~W}$;

- Rated current: $I_{o_{-} m} 4 \mathrm{~A}$;

- Switch frequency: $f_{s} 100 \mathrm{kHz}$;

- Inductor: $L_{3}=0.6 \mathrm{mH}$ and $L_{b}=1.8 \mathrm{mH}$;

- Capacitor: $C_{f}=250 u F$.

Fig. 15 shows the experimental waveforms of the gate driving signals and the inductor current at full load $\left(P_{o}=\right.$ $\left.400 \mathrm{~W}, P_{o}>P_{\text {in } 1 \max }+P_{\text {in } 2 \max }\right)$. The converter can work in operation mode $I$, in which sources 1 and 2 provide their maximum power to the load and $D_{y 3}$ changes automatically to supply the rest of the load power. The inductor current waveform of $L_{b}$ is shown in Fig. 15(a), and the inductor current waveform of $L_{3}$ is shown in Fig. 15(b).

Fig. 16 shows the experimental waveforms of the gate driving signals and the inductor current at half load $\left(P_{o}=250 \mathrm{~W}, P_{\text {in1_max }}<P_{o}<P_{\text {in1_max }}+P_{\text {in2_max }}\right)$. The converter can work in operation mode II, in which source 1 provides its maximum power $\left(P_{\text {in__max }}=135 \mathrm{~W}\right)$ to the load and $D_{y 2}$ changes automatically to supply the rest of the load power. As a result, source 3 does not do any work. 


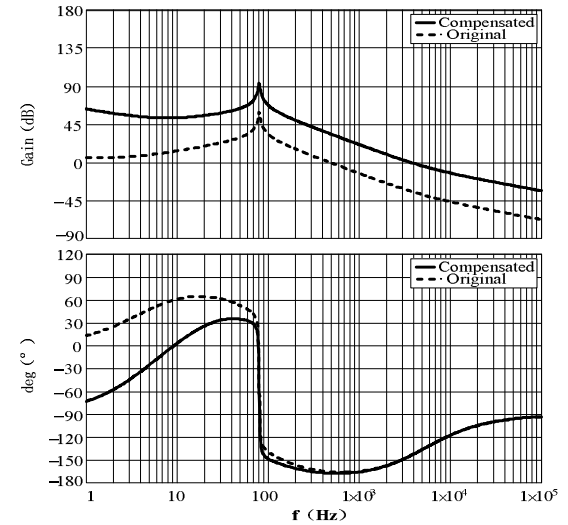

(a)
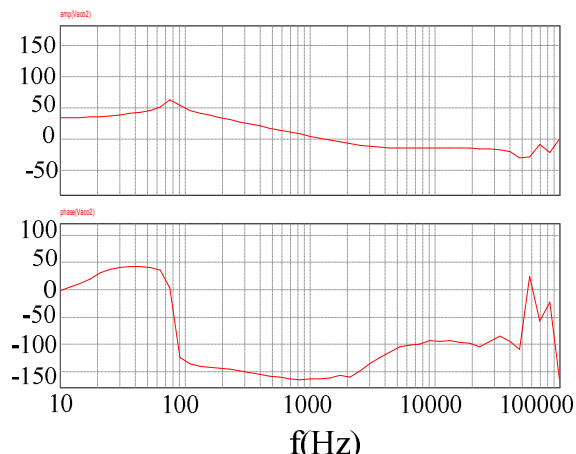

(b)

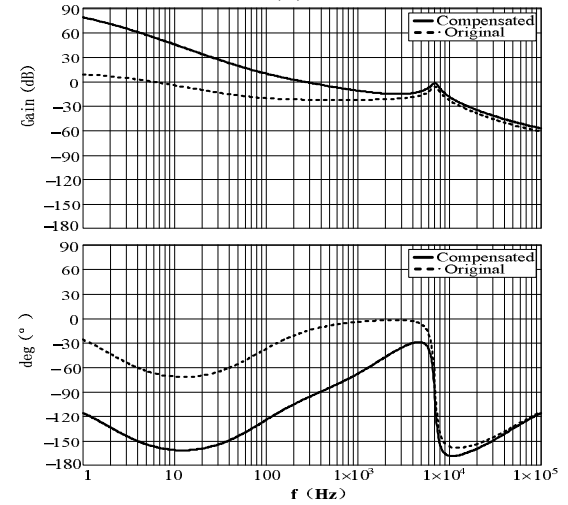

(c)
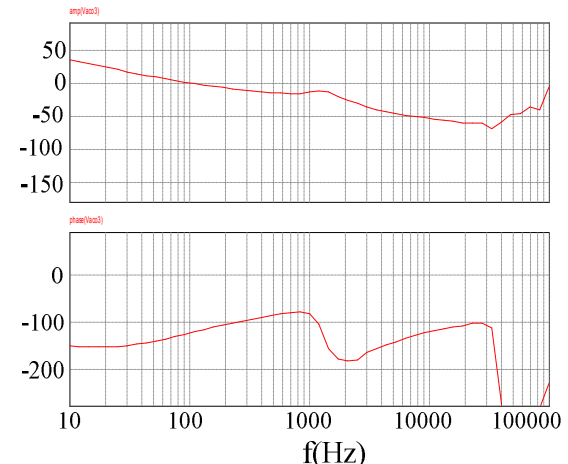

(d)

Fig. 14. Bode plots loop gains in operation mode III of (a) input current inner loop of source 1 by Mathcad (b) input current inner loop of source 1 by PSIM (c) output voltage outer loop by Mathcad (d) output voltage outer loop by PSIM.

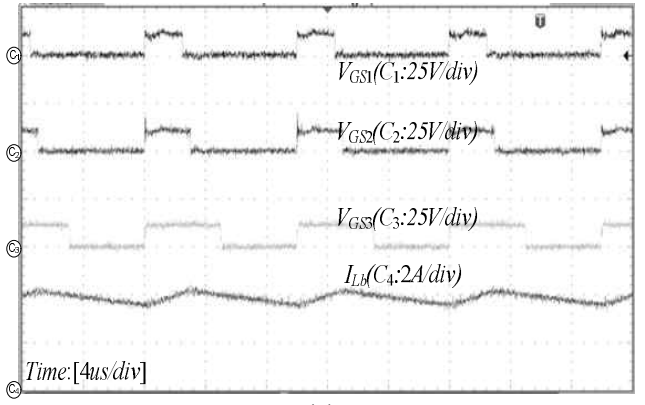

(a)

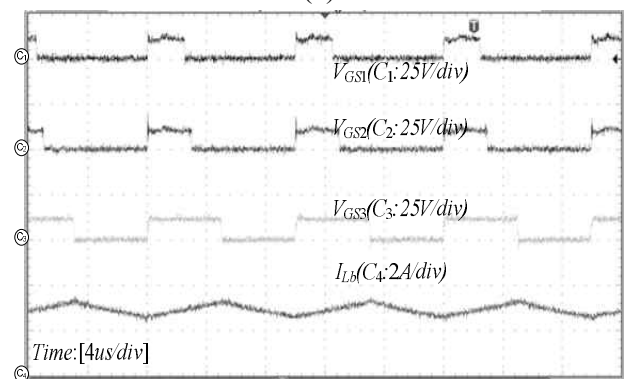

(b)

Fig. 15. Experimental waveforms in operation mode I of (a) gate driving signals and inductor current of $L_{b}$ (b) gate driving signals and inductor current of $L_{3}$

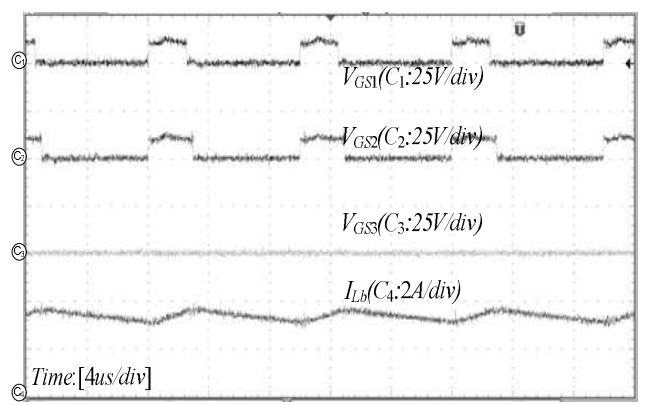

Fig. 16. Experimental waveforms in operation mode II.

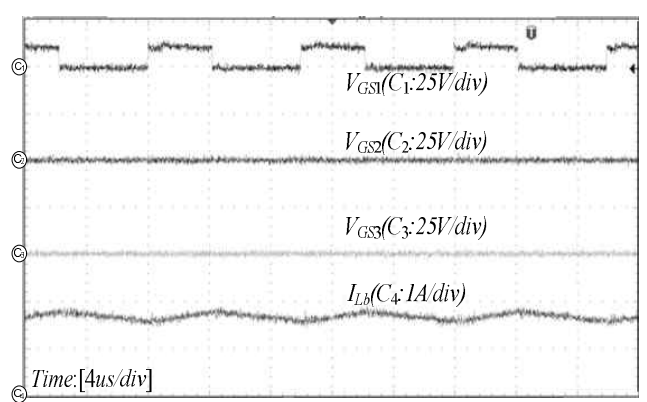

Fig. 17. Experimental waveforms in operation mode III.

Fig. 17 shows the experimental waveforms of the gate driving signals and the inductor current at light load $\left(P_{o}=120 \mathrm{~W}, P_{o}<P_{\text {inI_max }}\right)$. The converter can work in operation mode III, in which source 1 provides its power to the load alone and automatically keeps the output voltage constant. As a result, sources 2 and 3 do not do any work. 


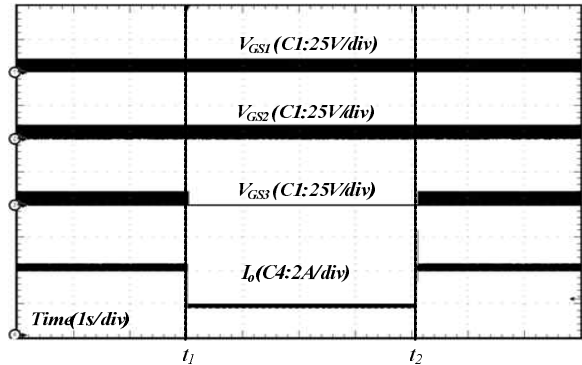

(a)

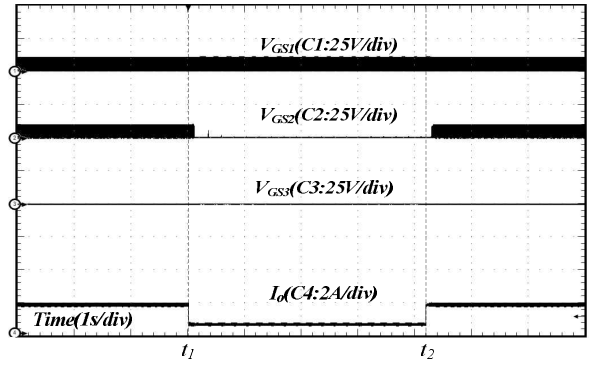

(b)

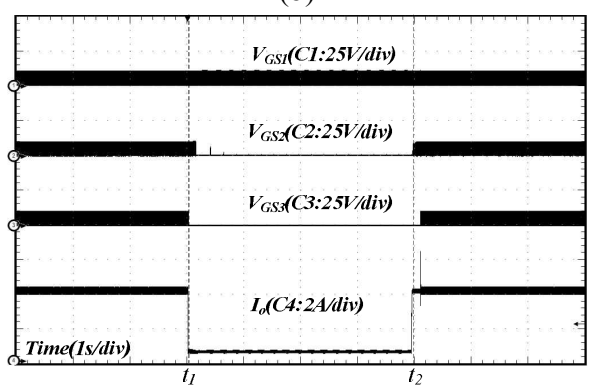

(c)

Fig. 18. Dynamic response waveforms between operation mode (a) I and II (b) I and III (c) II and III.

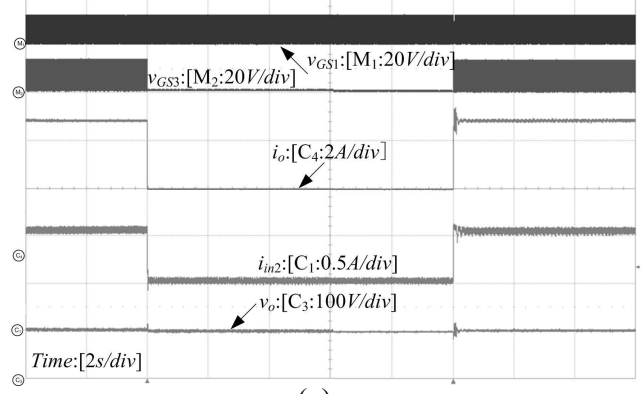

(a)

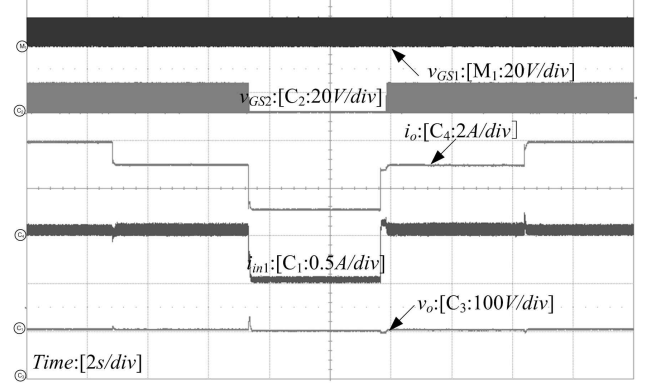

(b)

Fig. 19. Experimental waveforms of (a) $i_{o}, i_{i n 1}$ and $v_{o}$ among operation modes I and III (b) $i_{o}, i_{\text {in } 2}$ and $v_{o}$ among operation modes I and II.

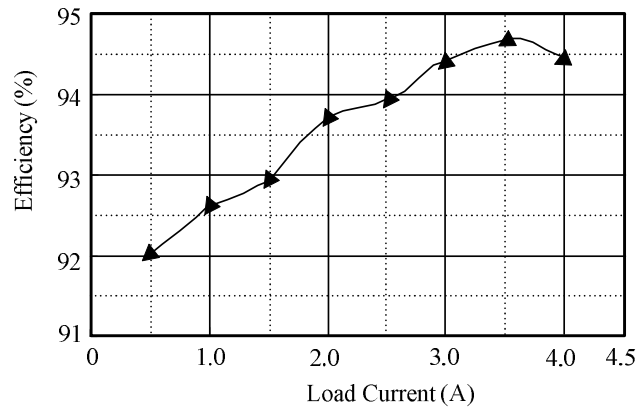

Fig. 20. Efficiency curve with load current change

Fig. 18 (a) shows the waveforms of the drive signals when the load current steps up and down between full load and $50 \%$ load. It can be seen that the converter switches from operation mode I to operation mode II. Fig. 18 (b) shows the dynamic response waveform when the load current steps down from $50 \%$ load to $25 \%$ load. The converter switches from operation mode II to operation mode I. Fig. 18(c) shows the dynamic response waveform when the load current steps down from full load to $25 \%$ load. The converter switches from mode I to mode III.

Fig. 19(a) gives the experimental waveforms of $i_{i n 2}$ and $v_{o}$ while $I_{o}$ steps down/up from $4 \mathrm{~A}$ to $2 \mathrm{~A}$. It can be seen that the system switches from mode I to mode III when $I_{o}$ decreases from $4 \mathrm{~A}$ to $2 \mathrm{~A}, i_{\text {in } 2}$ decreases to $0.5 \mathrm{~A}$ and $v_{o}$ is kept at $100 \mathrm{~V}$. Fig. 19(b) shows the experimental waveforms of $i_{i n 1}$ and $v_{o}$ while $I_{o}$ steps down/up among $4 \mathrm{~A}, 3 \mathrm{~A}$, and $1 \mathrm{~A}$. It can be seen that this converter operates in mode I and that $i_{i n 1}$ and $v_{o}$ are kept constant when $I_{o}$ decreases from $4 \mathrm{~A}$ to $3 \mathrm{~A}$. The system switches to mode III when $I_{o}=1 \mathrm{~A}$, and $i_{i n 1}$ decreases to $0.6 \mathrm{~A}$ and $v_{o}$ is kept at $100 \mathrm{~V}$.

From these experimental results, it can be seen that the system can operate stably in each operation mode and that it can switch smoothly among the three operation modes with the obtained ICR and OVR. They also verify the validity of the regulator design approach.

The efficiency of the three-input converter is tested in the Lab. Fig. 20 shows the curve of the efficiency with the change in the load current. From Fig.20, it can be seen that the efficiency will reach its maximum in operation mode I, and that it is $94.7 \%$.

\section{GENERATION OF THE MULTI-INPUT BUCK/BOOST/BUCK-BOOST CONVERTER}

According to the rule of composition and the rule of nesting, the three-input buck/boost/buck-boost converter is formed by a boost cell and a buck/buck-boost hybrid cell, which is constructed by a buck-boost cell with a built-in buck cell. As a result, there are several paths to extend this three-input converter to the corresponding multi-input converter, which is shown in Fig. 21. The boost cell and the hybrid cell can both be extended. In addition, the buck cell in the hybrid cell can also be extended along. 


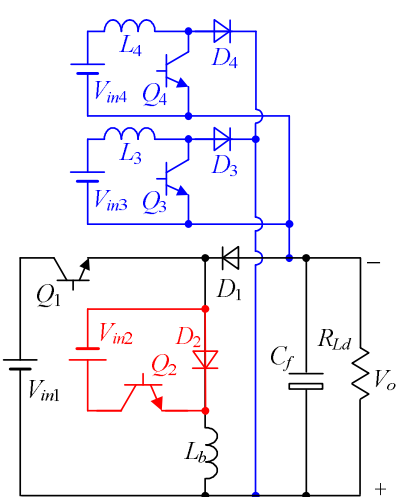

(a)

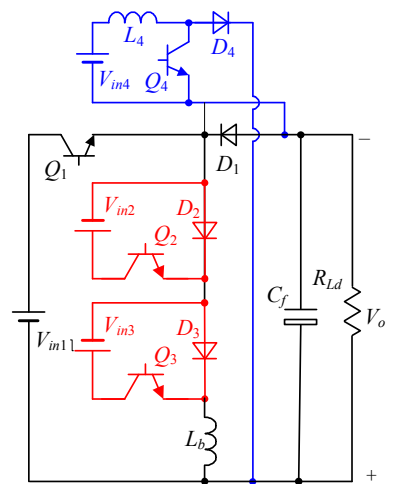

(b)

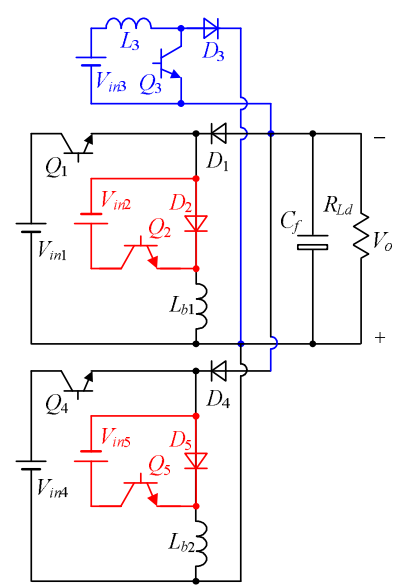

(c)

Fig. 21. Generation of multiple-input buck/boost/ buck-boost $\mathrm{dc} / \mathrm{dc}$ converter with (a) boost cell extension (b) buck cell extension (c) hybrid cell of buck/buck-boost extension.

\section{CONCLUSIONS}

This paper proposed a novel three-input buck/boost/buck-boost converter, which can be used in applications with various values of input voltage. The power sources in this converter can deliver power to the load either simultaneously or individually in one switching period. The steady relationship and the power management strategy of this converter have been derived. With decoupling technology, the modeling and regulator design can be obtained under multi-loop control modes. The presented control strategy and the small-signal modeling are verified on a $400 \mathrm{~W}$ buck/boost/buck-boost three-input $\mathrm{dc} / \mathrm{dc}$ converter. From these experimental results, it can be seen that the system can operate stably in each operation mode and switch smoothly among the three operation modes with the obtained ICR, ICR2 and OVR. They also verify the validity of the regulator design approach.

Finally, three generating methods for a multiple-input buck/boost/buck-boost converter are given. This method can be extended to the other multiple-input $\mathrm{dc} / \mathrm{dc}$ converters.

\section{ACKNOWLEDGMENT}

This work is supported by The Specialized Research Fund for the Doctoral Program of Higher Education of China (award number 20110009120032), a Class General Financial Grant from the China Postdoctoral Science Foundation (award number 2011M500225) and a Funds for DELTA Science \& Technology Educational Development (award number DREG2011010).

\section{REFERENCES}

[1] F. Iannone, S. Leva, and D. Zaninelli, "Hybrid photovoltaic and hybrid photovoltaic-fuel cell system: Economic and environmental analysis," IEEE Power Engineering Society General Meeting, pp. 1503-1509, 2005.

[2] Z. H. Jiang, "Power management of hybrid photovoltaic-fuel cell power systems," IEEE Power Engineering Society General Meeting, pp. 1-6, 2006.

[3] W. G. Imes and F. D. Rodriguez, "A two-input tri-state converter for spacecraft power conditioning," AIAA IECEC, pp. 163-168, 1994.

[4] F. D. Rodriguez, "Analysis and modeling of a two-input dc-dc converter with two controlled variables and four switched networks," Intersociety Energy Conversion Engineering Conference, pp. 11-16, 1996.

[5] B. G. Dobbs and P. L. Chapman, "A multiple-input dc-dc converter topology," IEEE Power Electron. Letter, Vol. 1, No. 1, pp. 6-9, Mar. 2003.

[6] N. D. Benavides and P. L. Chapman, "Power budgeting of a multiple-input buck-boost converter," IEEE Trans. Power Electron., Vol. 20, No. 6, pp. 1303-309, Nov. 2005.

[7] H. Matsuo, W. Z. Lin, and F. Kurokawa, "Characteristics of the multiple-input dc-dc converter," IEEE Trans. Ind. Electron., Vol. 51, No. 3, pp. 625-631, Jun. 2004.

[8] K. Kobayashi, H. Matsuo, and Y. Sekine, "Novel solar-cell power supply system using a multiple-input dc-dc converter," IEEE Trans. Ind. Electron., Vol. 53, No. 1, pp. 281-286, Feb.2006.

[9] Y. M. Chen, Y. C. Liu, and S. H. Lin, "Double-input PWM dc-dc converter for high/low voltage sources," IEEE Trans. Ind. Electron., Vol. 53, No. 5, pp.1538-1544, Oct. 2006.

[10] Y. M. Chen, Y. C. Liu, S. C. Hung, and C. S. Cheng, "Multi-input inverter for grid-connected hybrid $\mathrm{PV} /$ wind power system," IEEE Trans. Power Electron., Vol. 22, No. 3, pp. 1070-1077, May 2007.

[11] K. P. Yalamanchili and M. Ferdowsi, "Review of multiple-input dc-dc converters for electric and hybrid vehicles," IEEE Vehicle Power and Propulsion Conference (VPPC), pp. 160-163, 2005.

[12] A. Kwasinski and P. T. Krein, "Multiple-input dc-dc converters to enhance local availability in grids using distributed generation resources," IEEE APEC, pp. 1657-1663, 2007.

[13] A. D. Napoli, F. Crescimbini, S. Rodo, and L. Solero, "Multiple input dc/dc converter for fuel-cell powered hybrid vehicles," IEEE PESC, pp. 1685-1690, 2002.

[14] L. Solero, A. Lidozzi, and J. A. Pomilio, "Design of multiple-input DC-DC power converter for hybrid vehicles," IEEE Trans. Power Electron., Vol. 20, No. 5, pp. 1007-1016, Oct. 2005.

[15] Y. M. Chen, Y. C. Liu, and T. F. Wu, "Multi-input dc-dc 
Converter Based on the multiwinding transformer for renewable energy applications," IEEE Trans. Ind. Appl., Vol. 38, No. 4, pp. 1096-1104, Jul./Aug. 2002.

[16] A. S. W. Leung, H. S. H. Chung, and T. Chan, "A ZCS isolated full-bridge boost converter with multiple-inputs," IEEE PESC, pp. 2542-2548, 2007.

[17] Y. M. Chen, Y. C. Liu, and T. F. Wu, "Multi-input dc-dc converter based on the flux additivity," IEEE IAS, pp. 1866-1873, 2001.

[18] Y. M. Chen, Y. C. Liu, and T. F. Wu, "Multi-input converter with power factor correction, maximum power point tracking, and ripple-free input currents," IEEE Trans. Power Electron., Vol. 19, No. 3, pp. 631-639, May 2004.

[19] H. J. Chiu, H. M. Huang, L. W. Lin, and M. H. Tseng, "A Multiple-input DC/DC converter for renewable energy system," IEEE Int. Conf. Industrial Technology, pp. 1304-1308, 2005.

[20] Yan Li and Xinbo Ruan, "Synthesis of multiple-input DC/DC converters," IEEE, Trans. Power Electron, Vol. 25, No. 9, pp.2372-2385, Sep. 2010.

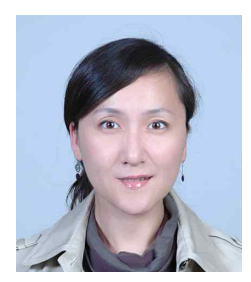

Yan Li was born in Heilongjiang Province, China, in 1977. She received her B.S. and M.S. in Electrical Engineering from Yanshan University, Qinhuangdao, China, in 1999 and 2003, respectively, and her Ph.D. in Electrical Engineering from the Nanjing University of Aeronautics and Astronautics, Nanjing, China, in 2009. From 1999 to 2009, she was at Yanshan University. Since 2009, she has been in the School of Electrical Engineering, Beijing Jiaotong University, Beijing, China. Her current research interests include multiple-input $\mathrm{dc} / \mathrm{dc}$ converters, renewable power systems, and PV grid-tied systems.

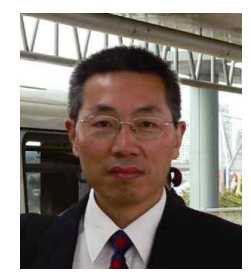

Trillion Q. Zheng (M'06-SM'07) was born in Jiangshan, Zhejiang Province, China, in 1964. He received his B.S. in Electrical Engineering from Southwest Jiaotong University, Sichuan, China, in 1986, and his M.S. and Ph.D. in Electrical Engineering from Beijing Jiaotong University, Beijing, China, in 1992 and 2002, respectively. He is currently a University Distinguished Professor at Beijing Jiaotong University, China. He directs the Center for Electric Traction, founded by the Ministry of Education, China. His current research interests include the power supplies and AC drives of railway traction systems, high performance, low loss power electronics systems, PV converters and control, and active power filter and power quality corrections. He holds 17 Chinese patents, and has published over 60 journal articles and more than 100 technical papers in conference proceedings. From 2003 to 2011, he served as Dean in the School of Electrical Engineering, Beijing Jiaotong University. He is currently the Deputy Director of the Beijing Society for Power Electornics and a Member of the Executive Committee of the China Electrotechnical Society. He received an Excellent Teacher Award from the Beijing Government (1997), and a Youth Award from the Railway Science and Technology of Zhan Tianyou (2005). He was a laureate of the Youth Elite of Science and Technology of the Railway Ministry of China (1998) and of the Zhongda Scholars for Power Electronics and Motor Drives of the Delta Environmental and Educational Foundation (2007).

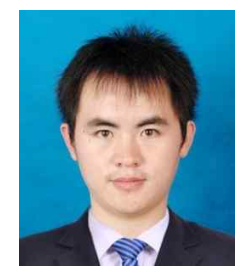

Chuang Zhao was born in Heilongjiang Province. He received his B.S. and M.S. in Electrical Engineering from Yan Shan University, Qinhuangdao, China, in 2009 and 2012, respectively. His current research interests include spacecraft power systems.

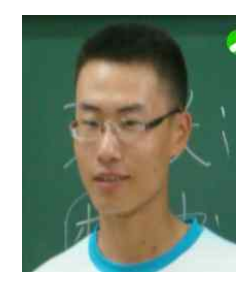

Jiayao Chen was born in Shanxi Province. $\mathrm{He}$ received his B.S. in Electrical Engineering from Beijing Jiaotong University, Beijing, China in 2012. His current research interests include renewable power systems. 